\title{
A relação entre ética e educação em Karl Marx
}

\author{
Diretor do Centro de Ciências Humanas e da Educação da Universidade \\ Estadual do Norte do Paraná, Campus Jacarezinho \\ Doutor em Educação pela UNICAMP
}

\section{Resumo}

A Educação e a Ética estão presentes de maneira explícita na produção teórica de Karl Marx. Ambas reivindicam a possibilidade da classe trabalhadora ter consciência de sua situação efetiva, ter conhecimento crítico dos mecanismos do modo de produção dominante, para exercer sua missão histórica. Uma Ética crítica e uma Educação revolucionária são fundamentais no processo de superação da educação e da moral capitalista que reduzem o ser humano a uma individualidade mutilada, mercantil, não permitindo o pleno desenvolvimento das suas capacidades criativas e o livre desenvolvimento de todos os individuos.

Palavras-chave: Marxismo; Ética; Educação.

\begin{abstract}
Education and Ethics are present explicitly in theoretical work of Karl Marx. Both claim the possibility of the working class aware of his actual situation, to have critical knowledge of the mechanisms of the dominant mode of production, to carry out its historic mission. An ethics review and a revolutionary education are fundamental in the process of overcoming the capitalist moral education and that reduce an individual human being mutilated, mercantile, not allowing the full development of their creative abilities and the free development of all individuals.
\end{abstract}

Key-words: Marxism; Ethics; Education. 
discussão sobre os fundamentos éticos no marxismo tem como
primeiro pressuposto as condições materiais efetivas
historicamente determinadas, ou seja, "parte-se dos homens, da sua atividade real; a partir do seu processo de vida real”, as suas condições reais de existência. É a partir da análise crítica objetiva, da situação concreta, que se pode fazer um juízo de valor das representações e ações humanas. Ou seja, a ética tem um caráter social e histórico.

Como as demais ciências, a ética se defronta com fatos. Que estes sejam humanos implica, por sua vez, que sejam fatos de valor. Mas isso não prejudica em nada as exigências de um estudo objetivo e racional. A ética estuda uma forma de comportamento humano que os homens julgam valiosos e, além disso, obrigatório e inescapável. Mas nada disso altera minimamente a verdade de que a ética deve fornecer a compreensão racional de um aspecto real, efetivo, do comportamento dos homens. (SÁNCHEZ VÁZQUEZ, 1998, p. 12)

Partindo da análise da maneira como os homens produzem seus meios de existência, a ética marxista visa explicar as ações concretas dos homens.

\begin{abstract}
Não partimos do que os homens dizem, imaginam e representam, tampouco do que eles são nas palavras, no pensamento, na imaginação e na representação dos outros, para depois se chegar aos homens de carne e osso; mas partimos dos homens em sua atividade real, é a partir de se processo de vida real que representamos também o desenvolvimento dos reflexos e das repercussões ideológicas desse processo real [...]. São os homens que produzem suas representações, suas ideias, etc., mas os homens reais, atuantes, tais como são condicionados por um determinado desenvolvimento de suas forças produtivas e das relações que a elas correspondem [...]. A consciência nunca pode ser mais que o ser consciente; e o ser dos homens é o seu processo de vida real [...] Não é a consciência que determina a vida, mas sim a vida que determina a consciência. (MARX; ENGELS, 2002, p. 19-20)
\end{abstract}

No modo capitalista de produção, a “consciência”, as “representações” são determinadas pela exploração do trabalho, pela propriedade privada dos meios de produção. Esta estrutura de sociedade produz todo tipo de desigualdade, de exploração, de dominação da natureza e de classe, praticada por uma classe dominante, que se utiliza de representações para justificar seus interesses, de manutenção do “estado atual de coisas”. A 
crítica ética marxista defende a tese que toda transformação real da sociedade produz uma nova moral, um novo costume, como historicamente tem acontecido. É por isso que tal ética não pode ser abstrata e geral, mas de classe. Tal ética é, por um lado, negativa, no sentido de criticar os modelos éticos dominantes e, por outro lado, é positiva, prospectiva e propositiva, no sentido de pensar e propor novas formas de ações no sentido de transformação das condições materiais de existência, das forças e relações produtivas. Nas sociedades de classes os juízos éticos e seus fundamentos diferem segundo as classes.

Os pensamentos da classe dominante são também, em todas as épocas, os pensamentos dominantes [...] a classe que é o poder material dominante numa determinada sociedade é também o poder espiritual dominante [...] a classe que dispõe dos meios de produção material dispõe também dos meios de produção intelectual. (MARX; ENGELS, 2002, p. 48)

Por isso, na sociedade capitalista, dividida em classes antagônicas, não há possibilidade de uma ética universal. Só é possível um ser explorado defendendo um mesmo princípio daquele que o explora por uma imposição ideológica que camufla as reais condições de vida de ambos. O marxismo defende, em sua concepção ética, a superação da exploração humana e da divisão de classes.

Para se chegar à conquista de uma moral realmente humana, subtraída a todos os antagonismos de classes ou mesmo à sua recordação, teremos, antes, de alcançar um tipo de sociedade na qual não somente se tenha abolido o antagonismo das classes, mas também tenha sido esse antagonismo, além de abolido, esquecido e afastado das práticas da vida. (ENGELS, 1976, p. 79)

E, se a história é um movimento de superação, então é preciso superar o egoísmo e o individualismo justificados pela ética capitalista. A ética capitalista teve seu momento importante quando justificou a luta para libertar o homem do jugo do feudalismo justificando um estado democrático e humanista. Porém, desde que se tornou a ética da classe dominante e desconheceu as camadas populares da população, com cuja ajuda havia derrotado o feudalismo e chegado ao poder, o individualismo capitalista se 
converteu em um princípio hostil a uma sociedade verdadeira e universalmente emancipada. Isto só será superado com a criação da propriedade social sobre os meios de produção:

Então cessa a luta pela existência individual [...] As condições de vida que cercam ao homem, e que até agora o dominavam passam, a partir desse instante, sob seu domínio e seu mando, e o homem, ao converter-se em dono e senhor de suas próprias relações sociais, se converte, pela primeira vez, em senhor consciente e efetivo da natureza (ENGELS, 1976, p. 265-266).

Assim, o princípio individualista de relações entre os homens será superado pelo princípio: “A cada um segundo suas possibilidades; a cada um segundo as suas necessidades”. Isso só poderá ser efetivado num movimento de crítica, resistência, desmascaramento e superação dos imperativos da competição, da acumulação, da maximização dos lucros que regem não apenas todas as transações econômicas, mas as relações sociais em geral "específicas" do modo de produção capitalista. Tal modo de produção, apesar de se apresentar como uma teoria e prática emancipatórias, não eliminou a exploração do homem pelo homem. Não fez mais que modificar as formas da exploração, pois está fundado nela: substituiu a exploração feudal, de servidão, encoberta com ilusões religiosas e políticas, pela exploração capitalista, desavergonhada, direta e dura.

A ética marxista, fundamentada na liberdade como autodeterminação, por sua vez, na sua análise crítica da totalidade das ações humanas, procura compreender o movimento que se apresenta como real proposta de criação de novas relações humanas, no sentido de propiciar aos homens a superação da exploração, do “estado atual de coisas”. Tal domínio só se realizará completamente com a substituição do modo de produção capitalista por uma forma de associação, pois, como diz Marx e Engels (2001, p. 92) “é somente na comunidade que o indivíduo possui os meios de desenvolver suas faculdades em todos os sentidos; é somente na comunidade que a liberdade pessoal é possível”. Neste sentido, a fundamentação ética marxista consiste em identificar-se com a classe trabalhadora em sua educação, organização e luta contra a exploração e opressão capitalista. 
Para vencer a resistência da classe dominante só há um meio: encontrar, educar e organizar para a luta, na própria sociedade que nos rodeia, às forças que podem e, por sua situação social, devem formar a força capaz de varrer o velho e criar o novo (LENIN. In: SHISKHIN, 1966, p. 404).

A tese fundamental da ética marxista expressa a relação entre o indivíduo e a sociedade, a forma na qual aquele se integra e se realiza aos interesses sociais, coletivos. Tal princípio, muito mais que matéria de estudo e conhecimento, deve ser convertido em profunda convicção e prática, servindo, assim, de força motriz para ser concretizado ao longo do processo histórico.

O indivíduo isolado, que se mostra indiferente aos fenômenos sociais, não pode ser, de forma alguma, o eixo lógico do código moral socialista. Nossa conduta se deve medir unicamente pelos interesses da coletividade e de cada um de seus membros. (MAKARENKO. In: SHISKHIN, 1966, p. 63).

Por isso, mesmo se a finalidade da ética é investigar as ações humanas, ela posse interferir nelas. O marxismo não nega as atitudes morais efetivas dos homens, pois elas sempre se constituíram fundamentais na prática humana. Porém, o marxismo não parte de um simples protesto moral, mas de uma crítica científica, racional, imanente, propositiva, de análise do "estado atual de coisas", no sentido de buscar apreender a realidade social humana, como condição necessária de sua transformação. Por isso, o curso que tomarão os acontecimentos e o desenvolvimento da sociedade dependem, em grande medida, dos fundamentos éticos e da práticas morais dos seres humanos. Segundo Schaff (2001, p. 154), “o futuro é obra do homem. No cenário atual vemos o homo autocreator, o homem criador do seu próprio destino e que esteve presente durante todo o desenvolvimento histórico".

O marxismo apresenta uma abordagem totalmente radical da questão da ética, pela sua visão prospectiva de transformação radical nas condições mesmas sob as quais se processam as reflexões sobre a totalidade do comportamento e ações humanas. Daí o seu caráter não messiânico e profético, de previsibilidade fatalista para a história humana. Se no 
pensamento marxista há uma ideia básica, que não é idealista nem normativo-prescritiva, é que, seu fundamento ético se constitui na crítica e na proposta de luta na construção de uma organização social mais elevada.

\begin{abstract}
A humanidade só enfrenta as tarefas que pode resolver, pois, se se considera mais atentamente, se chegará à conclusão que a própria tarefa só aparece onde as condições materiais de sua solução já existem, ou, pelo menos, são captadas no processo de seu devir. (MARX, 2000, p. 52)
\end{abstract}

Se a ética marxista, além de crítica, é também finalística, tal teleologia não é determinista, mas tem sentido de necessidade, possibilidade, de construção no processo vital. Daí que a consciência da necessidade ativa de compreensão do desenvolvimento histórico e da participação interventiva e transformadora é que caracterizam o fundamento e o exercício da liberdade humana (cf. SÁNCHEZ VÁZQUEZ, 1998, p. 107).

A finalidade última do marxismo é a emancipação humana, isto é, a construção de uma realidade especificamente humana, que não nascerá naturalmente e nem somente pelo esgotamento das forças capitalistas, mas pelo enfrentamento, protesto, indignação, denúncia e ruptura com toda forma de alienação, de “reificação”, de exploração do homem pelo homem, da ordem estabelecida. Assim "a história em si nada é senão a atividade dos homens que buscam seus fins" e o fim da ética marxista é justificar a possibilidade a todos os indivíduos humanos igual aspiração à emancipação a uma mesma pretensão de satisfazer suas necessidades humanas ou como diz Saviani (2002, p. 48): “Agir de modo intencional significa agir em função de objetivos previamente definidos”. A ética marxista se fundamenta na ontologia, na filosofia do homem, na concepção de história, na visão política marxista, que considera a prática moral como uma forma de consciência social determinada economicamente, estabelecendo assim um vínculo prático, efetivo entre ela e os processos da vida social.

Enfim, tratar da ética no marxismo é tão difícil quanto querer negar nele tal dimensão, pois compreendemos que nenhuma afirmação sobre o marxismo poderá ser considerada concluída. O marxismo se prova na ação, 
daí só podermos falar de ética mediante a ação efetiva dos indivíduos humanos, em constante movimento, nas suas determinações materiais, históricas. Daí ser a ética essa reflexão crítica e radical no sentido de analisar os diversos movimentos históricos, suas efetivas e possíveis transformações, como ação do homem sobre as circunstâncias históricas.

A importância da dimensão ética e educativa em Marx, educação entendida no sentido amplo, como processo vital de existência humana, isto é, aquilo que caracteriza a sua especificidade de ser social, a saber, a capacidade de conhecer, de ter ciência do real e de, portanto, intervir e transformá-lo de forma responsável e consciente. A apropriação de conhecimento como resultado de um longo processo que reflete as condições materiais históricas e os interesses e valores sociais. Educar significa, como diz Goergen (2001, p. 36): “Garantir ao ser humano a possibilidade de interferir e, porque não, orientar os rumos de sua história individual e coletiva".

O direcionamento da educação dentro dos determinantes históricos do modo de produção capitalista, que conduz a educação a uma mera qualificação técnica ou profissionalizante, marcadas pela lógica da competição, pelos interesses do "mercado", do acúmulo material e do sucesso mercantil, só pode ser transformado e superado mediante uma educação revolucionária, ou seja, com referenciais filosóficos, políticos, éticos revolucionários, instrumentos efetivos de tomada de consciência e possibilidade de intervenção e transformação da realidade. Daí a articulação entre teoria e prática.

Para que a teoria saia do estado propriamente teórico e se converta em verdade prática é necessário que ela seja assimilada por contingentes cada vez mais amplos de sujeitos sociais, emergindo como agentes efetivos da prática histórica. E isso pressupõe um trabalho educativo sem o qual resultará impossível a mobilização da população para a realização das transformações necessárias, o que põe na ordem do dia a problemática desenvolvida pela filosofia dialética da educação com base na filosofia da práxis. (SAVIANI. In: FREITAS, 1996, p. 183) 
Portanto, a crítica ao modo de produção capitalista requer, para sua superação, uma efetiva proposta pedagógica interventiva e transformadora, um compromisso ético, político e social dos educadores, dos educandos, da escola. É aqui que entra a fundamental dimensão ético-política da educação, isto é, de "não ajustamento", de "não adaptação" ao sistema dominante vigente, mas de ser uma mediação na formação de uma racionalidade consciente, interventiva, de "fortalecer a resistência” no desenvolvimento do processo social, nas várias dimensões humanas, especialmente a política, que significa agir sobre o mundo e compreender essa ação.

Quando afirmo que a educação é sempre um ato político, quero como isso frisar que a educação cumpre sempre uma função política. Mas é preciso não identificar essa função política com outra função que a educação cumpre, que é a técnica. Estas funções não se identificam, elas se distinguem. Mas, embora distinguíveis, são inseparáveis, ou seja: a função técnica é sempre subsumida por uma função política. (SAVIANI, 2002, p. 212)

Neste sentido, a educação e a ética se constituim numa atitude política consciente, coerente com os princípios da emancipação humana ou no dizer de Mészaros: “O papel da educação, orientado pela única perspectiva positivamente viável de ir para além do capital, é absolutamente crucial a este propósito”.

Por isso, a necessidade de uma Filosofia da Educação como sua missão, segundo Nunes (2003, p. 38-39) de "produzir cidadania, consciência histórica, responsabilidade moral, elevação ética, participação política e sensibilização estética nas gerações presentes e futuras”. Daí que a educação não pode ser compreendida à margem da história, mas ser esta reflexão-ação dos problemas postos pelo desenvolvimento histórico, nos determinantes do modo e relação de produção vigentes. Desta forma, é impossível separar a educação da questão dos determinantes econômicopolítico-cultural, pois ela não é um processo neutro, mas comprometida com o movimento social e histórico.

O trabalho educativo é o ato de produzir, direta e intencionalmente, em cada indivíduo singular, a humanidade 
que é produzida historica e coletivamente pelo conjunto dos homens. Assim, o objeto da educação diz respeito, de um lado, à identificação dos elementos culturais que precisam ser assimilados pelos indivíduos da espécie humana para que estes se tornem humanos e, de outro lado e concomitantemente, à descoberta das formas mais adequadas para atingir esse objetivo (SAVIANI, 1991, p. 21).

Neste sentido, a educação cumpre a necessária missão de uma contundente crítica das concepções e práticas educacionais atreladas à lógica do capital, que tem no individualismo, no lucro, na exacerbada mercantilização, na desumana competição e na exploração do trabalho seus fundamentos. A educação capitalista não vai além da reprodução, legitimação e manutenção da ordem dominante vigente, incapaz de transcender os limites do capital. É neste contexto que surge a necessiade de pensar uma "educação para além do capital”1.

Porém, pensar uma alternativa educacional que seja formulada do ponto de vista da emancipação universal humana, mesmo diante da força do capital é um desafio possível, pelo fato do capitalismo, mesmo com toda sua força condicionante, ser limitado em relação à sua imposição sobre a produção das idéias e dos costumes. As idéias não são impostas e aceitas automaticamente; por isso, as idéias capitalistas como construções sócioeconômico-culturais históricas não são naturais, nem eternamente necessárias. Quer dizer, é no interior do próprio desenvolvimento do sistema capitalista que, ao mesmo tempo há uma manutenção da ordem vigente e nascem as idéias superadoras e construtoras de uma nova realidade. É na articulação da totalidade social do ser e do existir humanos que se realiza a dimensão política da educação.

Esta necessidade de compreensão da totalidade social humana é defendida por Marx nos seus escritos quando, por exemplo, denuncia a educação burguesa como despolitização dos trabalhadores, considerando

\footnotetext{
1 “Educação para além do capital”, texto do filósofo húngaro István Mészáros, escrito para a conferência de abertura do Fórum Mundial de Educação 2004, em Porto Alegre, depois publicado pela Boitempo em 2005, com o mesmo título. A educação é tratada no sentido amplo, como o processo vital de existência do homem, aquilo que caracteriza a sua especificidade de ser social, a saber, a capacidade de conhecer, de ter ciência do real e de, portanto, transforma-lo de forma consciente.
} 
“os trabalhadores como mercadoria”, naquilo que Marx (2004, p. 80) diz: “Com a valorização do mundo das coisas, aumenta em proporção direta a desvalorização do mundo dos homens”. Neste sentido, quanto mais o homem condiciona sua educação ao “mercado capitalista” menos hominizase e menos humaniza a natureza. O capital fica estabelecido como o fundamento da produção, da educação e da própria vida humana. Neste sentido:

A produção produz o homem não somente como uma mercadoria, a mercadoria humana, o homem na determinação da mercadoria; ela o produz, nesta determinação respectiva, precisamente como um ser desumanizado tanto espiritual quando corporalmente (MARX, 2004, p. 92-93).

Porém, para Engels (In: MARX; ENGELS, 1983, p. 80) “a miséria não só ensina o homem a rezar: também ensina a pensar e atuar”. Por isso, é fundamental tratar a questão da educação não desvinculada de toda produção espiritual e material da vida humana, pois sem pensar em uma transformação das condições objetivas nas quais o sistema dominante se impõe sobre a humanidade, não é possível conceber qualquer tipo de educação transformadora e podemos cair num discurso parenético, ou um superficial protesto moral. Falar de educação e de ética, do ponto de vista de Marx, exige uma atitude analítica crítica de todo sistema pautado no adestramento, na doutrinação, subordinação, servilismo, dependência, que transforma o ser humano em mercadoria, coisa, em ser alienado e propor alternativas de superação de tal condição. Marx, em uma das mais contundentes crítica sobre a forma capitalista de tratar o trabalhador:

Deforma (aleija) o trabalhador convertendo-o numa anomalia, levando-o artificialmente a desenvolver uma habilidade parcial à custa da repressão de um mundo de instintos [...] o indivíduo é mutilado e transformado no aparelho automático de um trabalho parcial [...] sua força individual do trabalho não funciona se não estiver vendida ao capital [...] a deformação física e espiritual é inseparável mesmo da divisão do trabalho em geral na sociedade [...] Subdividir um homem significa executá-lo, se merece a pena de morte, e se não a merece, assassiná-lo... A subdivisão do trabalho é o assassino de um povo (MARX, 1988, p. 270-272). 
O processo de produção de uma educação transformadora passa, antes de tudo, pelo debate entre uma teoria reflexivo-analítica, de esclarecimento racional, e uma prática consciente, possível, propositiva, aberta, possibilitando a todo ser humano ser sujeito capaz de compreender, se posicionar e intervir nos processos de produção da vida e da sociedade.

Produzir homens plenamente desenvolvidos" e "não deixar enfraquecer todas as forças físicas e morais [...] e o embrutecimento tanto sobre o organismo como sobre as faculadades mentais dos trabalhadores (ENGELS. In. MARX; ENGELS, 1983, p. 24-25).

Daí é imprescindível, como já vimos, a liberdade, como condição essencial de eliminação dos obstáculos à emancipação humana. Liberdade no sentido de não estar submetido a uma ordem que se diz única, natural e eterna, mas de pensar o diferente, o alternativo. Ser livre significa criar uma forma de consciência social que liberte dos limites restritos do controle do capital a própria vida e o modo de ser dos indivíduos, de modo que sejam estes capazes de pensar e fazer seu processo de existência.

A ação emancipatória torna-se efetiva quando articula a teoria, a reflexão analítica, com a ação consciente, metódica, politicamente determinada com a intencionalidade propositiva. Chamamos de emancipatória a perspectiva e prospectiva que visa a produzir autonomia crítica, cultural e simbólica, esclarecimento científico, libertação de toda forma de alienação e erro, de toda submissão, engodo, falácia ou pensamento colonizado, incapaz de esclarecer os processos materiais, culturais e políticos. Ao mesmo tempo em que liberta, aponta que emancipação significa também uma prática da autonomia ética, o ideal e propósito de construir valores que justifiquem nossas condutas morais, indica ainda a responsabilidade social pelas escolhas que fazemos, até constituir-se num ideal de elevação estética. De cultivo de ideais justos e carregados de generosa identificação com o que é bom, o belo, o adequado, o ideal de realização estética para todos. Por fim, emancipação significa coerência, autonomia, conviç̧ão e libertação política, a constituir-se em grupos e comunidades de pessoas esclarecidas pela ciência e motivadas pelos ideais e virtudes coletivas. (NUNES, 2003, p. 35-36)

Uma outra questão fundamental na construção de uma educação que seja transformadora é a convicção de que a história não é estática, é um movimento dinâmico, contraditório, que está sendo construída a cada dia 
por indivíduos que estão vivendo seu próprio momento histórico. Só assim é possível acreditar, possibilitar é fazer acontecer concretamente as mudanças, as transformações, aquilo que Mészáros (2005, p. 59) chama de “necessárias aspirações emancipadoras”. Para isso, o ser humano não pode se entrincheirar, se refugiar numa cômoda vida individualista e indiferente em relação à construção dos destinos da humanidade. Ainda mais, é preciso reagir contra toda forma de imitação, reprodução ou simples aceitação do já determinado. A história está para ser construída, com a utilização da capacidade humana criadora, inovadora e transformadora. É no momento histórico que estamos, no início do século XXI, que podemos “construir esperanças” nos diversos campos da vida e dar um sentido novo à história.

É preciso superar a forma capitalista de pensar, organizar a sociedade e resgatar os ideais socialistas e sua concepção de homem, de sociedade, de natureza como condição necessária de possibilidade de levar cada homem a uma nova forma de produzir a vida e construir a nova sociedade, mais elevada e humanizada. Isso não se realiza a partir de propostas reformistas, mas somente "com uma reestruturação radical das nossas condições de existência há muito estabelecidas e, por conseguinte, de 'toda a nossa maneira de ser’” (MÉSZÁROS, 2005, p. 60). ${ }^{2}$

Não há dúvida que qualquer proposta nova, também no campo educacional, se choca com discursos e práticas petrificadas, resignadas, que insistem em manter suas maneiras de pensar, organizar o processo educativo. Neste sentido, tem que prevalecer a atitude coerente de desafio, como já dissemos, e reagir a toda tentativa unilateral de limitar o homem a um "ser econômico", técnico, fatalmente destinado para se adaptar e servir ao mercado capitalista. Para isso, a fundamental contribuição da educação no processo de superação do efetivo estado atual do homem e da sociedade.

O papel da educação é soberano, tanto para a elaboração de estratégias apropriadas e adequadas pra mudar as condições objetivas de reprodução, como para a automudança consciente dos indivíduos chamados a concretizar a criação de uma ordem

\footnotetext{
${ }^{2}$ A citação se fundamenta em MARX, 1985, p. 137.
} 
social metabólica radicalmente diferente. É isso que se quer dizer com a concebida 'sociedade de produtores livremente associados'. Portanto, não é surpreendente que na concepção marxista a "efetiva transcendência da auto-alienação do trabalho" seja caracterizada com uma tarefa inevitavelmente educacional. (MÉSZÁROS, 2005, p. 65)

É por isso que, ao longo da nossa reflexão, além da constatação, da denúncia e da crítica a todas as formas de alienação, desumanização, reificação, fetichização, exploração humana, levadas a cabo de uma maneira radical pelo modo capitalista de produção e reprodução da vida, defendemos a possibilidade e necessidade histórica de ruptura, de superação de tal condição e de construção de novas relações entre o homem, a natureza e a sociedade, enfim a construção do "homem novo" e da nova sociedade. Nesse processo, a educação do trabalhador para o exercício da liberdade, da responsabilidade no sentido de tomar consciência da situação efetiva e da sua potencialidade humana de intervir e estabelecer o controle dos processos sociais vitais se faz necessária. O papel da educação, orientado nesta perspectiva de superar e ir “para além do capital” é absolutamente crucial para esse propósito.

A educação para além do capital visa uma ordem social
qualitativamente diferente. Agora não só é factível lançar-se
pelo caminho que nos conduz a essa ordem, como o é também
necessário e urgente. Pois as incorrigíveis determinações
destrutivas da ordem existente tornam imperativo contrapor aos
irreconciliáveis antagonismos estruturais do sistema do capital
uma alternativa concreta e sustentável para a regulação da
reprodução metabólica social, se quisermos garantir as
condições elementares da sobrevivência humana. O papel da
educação, orientado pela única perspectiva positivamente viável
de ir para além do capital, é absolutamente crucial a este
propósito. (MÉSZÁROS, 2005, p. 71-72)

Enfim, para insistir mais uma vez naquilo que defendemos em cada página do nosso texto, a verdadeira emancipação humana e social só será possível a partir da crítica radical e ruptura efetiva com todas as estruturas sociais, econômicas, políticas, culturais, educacionais desumanizantes. Daí que, lutar contra a exploração, a opressão, a dominação e a alienação, isto é, 
contra o domínio do capital, têm como tarefa educacional a "transformação social amplamente emancipadora”.

E nesse campo se articulam, como já dissemos, a missão de uma ética e de uma educação da praxis. Para ser uma educação e ética humanistas não basta colocar o homem, como uma abstração, no centro do campo da reflexão e ação; é preciso considerar o homem na sua concreticidade histórica, como efetividade e potencialidade; é preciso pensar, oportunizar a criação das condições indispensáveis para o seu desenvolvimento omnilataral, isto é, “intelectual, físico, tecnológico”. Tudo isso será concretizado se superarmos o passivismo conformista e acreditamos que há um horizonte novo, ilimitado, aberto à totalidade, não de maneira abstrata e a-histórica, mas propício para a construção de um mundo autenticamente humano e humanizado, onde cada indivíduo exerça a totalidade de sua capacidade produtiva, se aproprie da totalidade dos bens produzidos universalmente, participe da totalidade do seu processo educacional e político. A Ética, aqui tomada como um conjunto de valores que se postulam como inspiradores de nossas ações políticas revolucionárias e nos impulsionam a resistir aos apelos ideológicos de uma sociedade reificada na mercadoria, é um horizonte prospectivo e crítico, a direcionar nossas reais esperanças e qualificar nossas lutas e enfrentamentos.

\section{Referências}

ENGELS, Friedrich. Anti-Dühring. Rio de Janeiro: Paz e Terra, 1976, 231p.

GOERGEN, Pedro. Pós-modernidade, ética e educação. Campinas: Autores Associados, 2001, 95p.

LOMBARDI, José Claudinei; GOERGEN, Pedro (Orgs.). Ética e Educação: reflexões filosóficas e históricas. Campinas: Autores Associados, 2005, 179p.

LOMBARDI, José Claudinei; SAVIANI, Dermeval (Orgs.). Marxismo e educaşão: debates contemporâneos. Campinas: Autores Associados, 2005, 274p.

MAKARENKO, Anton Semiónovitch. Sobre a ética comunista. In: SHISKHIN, A. F. Ética. Buenos Aires: Cartago, 1966, 454p. 
MARX, Karl. Manuscritos econômico-filosóficos. São Paulo: Boitempo, 2004, 176p.

MARX, Karl; ENGELS, Friedrich. A ideologia alemã. São Paulo: Martins Fontes, 2002, 119p.

MARX, Karl. Introdução à Crítica da Economia Política. São Paulo: Nova Cultural, 2000, 413p.

MARX, Karl; ENGELS, Friedrich. A Sagrada Familia. Portugal/Brasil: Presença/Martins Fontes, 1976, 328p.

MARX, Karl. O Capital. v. I. São Paulo: Nova Cultural, 1988, 287p.

MARX, Karl. A miséria da filosofia. São Paulo: Global, 1985, 225p.

MÉSZÁROS, István. A educação para além do capital. São Paulo: Boitempo, 2005, $77 \mathrm{p}$.

NUNES, César. Educar para a Emancipação. Florianópolis: Sophos, 2003, 128p.

MARX, Karl; ENGELS, Friedrich. Textos sobre educação e ensino. São Paulo: Moraes, 1983, 98p.

SÁNCHEZ VÁZQUEZ, Adolfo. Ética. Rio de Janeiro: Civilização Brasileira, 1998, 260p.

SAVIANI, Dermeval. Filosofia da educação: crise da modernidade e o futuro da filosofia da práxis. In: FREITAS, Marcos Cezar (Org.). A reivindicação do futuro: trabalho, educação, política na globalização do capitalismo. São Paulo: Cortez; Bragança Paulista: USF-IFAN, 1996.

SAVIANI, Dermeval. Educação: do senso comum à consciência filosófica. Campinas: Autores Associados, 2002, 247p.

SCHAFF, Adam. A sociedade Informática. São Paulo: Brasiliense, 2001, 160p. 